Number (percentage) of premises of Wessex hospitals achieving goals for restrictions on smoking in 1981 and $1985^{\star}$

\begin{tabular}{|c|c|c|c|c|c|c|c|c|c|}
\hline \multirow[b]{3}{*}{ Area of premises } & \multirow{3}{*}{$\begin{array}{c}\text { Goal }(\% \text { of } \\
\text { floorspace } \\
\text { designated a } \\
\text { no smoking } \\
\text { area) }\end{array}$} & \multicolumn{8}{|c|}{ Type of hospital } \\
\hline & & \multicolumn{2}{|c|}{ Short stay } & \multicolumn{2}{|c|}{ Maternity } & \multicolumn{2}{|c|}{ Psychiatric } & \multicolumn{2}{|c|}{$\begin{array}{l}\text { Long stay and } \\
\text { geriatric }\end{array}$} \\
\hline & & $\begin{array}{c}1981 \\
(\mathbf{n}=60)\end{array}$ & $\begin{array}{c}1985 \\
(n=61)\end{array}$ & $\begin{array}{c}1981 \\
(n=9)\end{array}$ & $\begin{array}{c}1985 \\
(n=7)\end{array}$ & $\begin{array}{c}1981 \\
(n=16)\end{array}$ & $\begin{array}{c}1985 \\
(\mathbf{n}=32)\end{array}$ & $\begin{array}{c}1981 \\
(n=29)\end{array}$ & $\begin{array}{c}1985 \\
(n=45)\end{array}$ \\
\hline Warc & 100 & $42(70)$ & $51(8$ & $9(100)$ & $7(100)$ & $5(33)$ & $11(35)$ & $16(54)$ & $32(70)$ \\
\hline Day rooms & 60 & $10(16)$ & $23(38)$ & $1(13)$ & $1(14)$ & $1(8)$ & $9(27)$ & $3(11)$ & $20(45)$ \\
\hline Outpatient departmen & 100 & $48(80)$ & $60(98)$ & $9(100)$ & $5(67)$ & $8(47)$ & $22(68)$ & $21(71)$ & $39(87)$ \\
\hline Public waiting areas & 100 & $35(58)$ & $52(86)$ & $9(100)$ & $6(80)$ & $2(14)$ & $11(33)$ & $19(65)$ & $31(68)$ \\
\hline
\end{tabular}

^Numbers of premises in 1985 vary from those in 1981 according to available facilities.

psychiatric hospitals did not have smoke free eating areas.

Coffee lounges and rest rooms - Less than one third of the premises had achieved their goal.

\section{SALE OF CIGARETTES}

Seven $(11 \%)$ of the short stay hospitals and $12(37 \%)$ of the psychiatric hospitals sold cigarettes to patients; none of the maternity hospitals did so. This represented a decrease since 1981. The proportion of long stay units selling cigarettes, however, had increased. Some short stay, psychiatric, and long stay hospitals also sold cigarettes to visitors and staff.

\section{Comment}

Considerable progress was made in restricting smoking in health service premises in Wessex after 1981. In some key areas, however, progress was disappointing. Most people in all social groups are now non-smokers, 5 yet most hospital day rooms allow smoking. The need to provide smoke free day rooms should be considered when new buildings are being planned, especially long stay and psychiatric premises.

Sales of cigarettes to patients should be restricted to long stay hospitals, and low tar brands should be offered. One district in Wessex already does this, suggesting that it is a realistic goal.

Most NHS staff are non-smokers, yet many more premises offer rest areas for staff where smoking is permitted than offer smoke free areas. The NHS, as an important employer, has a considerable opportunity to promote non-smoking by providing smoke free working environments and advice and help to employees who wish to give up smoking. Handbooks and induction courses for staff are underused as opportunities to communicate policies on smoking to staff. The adoption of such policies in health service premises by health authorities will lead to change only if clear goals are set and progress towards these is monitored. A regional review can promote change by providing useful information for districts.

\section{Robert JL, Smith LA. Who's for health: public opinion on policies for health Health Services fournal 1987 Oct 22:1230-1. \\ 2 Department of Health and Social Security. Health services management: promoting non-smoking on NHS premises. London: DHSS, 1985. $(\mathrm{HC}(85) 22$.) 3 Wessex Positive Health Team. Smoking prevention in Wessex health premises. Winchester: Wessex regional health authority, 1982. (Lifeline report No 4.) 4 Catford JC, Nutbeam D. Smoking in hospitals. Lancet 1983;ii:94-6. \\ 5 Office of Population Censuses and Surveys. Cigarette smoking 1972 to 1986. OPCS Monitor 1988; No 1. (SS 88/1.)}

(Accepted 24 October 1988)

\section{Recurrent cardiovascular collapse due to surreptitious ingestion of propranolol}

\author{
G L Warwick, J M Boulton-Jones
}

Fourth Floor Medical Unit, Glasgow Royal Infirmary, Glasgow G4 0SF

G L Warwick, MRCP, medical registrar

J M Boulton-Jones, FRCP, consultant physician

Correspondence to:

Dr G L Warwick, Renal

Unit, Glasgow Royal

Infirmary, Glasgow G4 0SF.

BrMed f 1989;298:294-5 propranolol.

\section{Case report}

Self poisoning can usually be diagnosed without difficulty, but sometimes patients deliberately conceal the ingestion of drugs and present with a confusing clinical picture. ${ }^{1}$ Intensive investigation may then be needed and inappropriate treatment given. We present a case of repeated surreptitious self poisoning with

In January 1985 a 28 year old woman presented with "dizziness." She was hypotensive (blood pressure $70 / 30 \mathrm{~mm} \mathrm{Hg}$ ) with a regular bradycardia. An electrocardiogram showed a junctional bradycardia (45 beats/minute), absent $P$ waves, and a broadened QRS complex. Her condition improved after she received intravenous atropine: the junctional rate

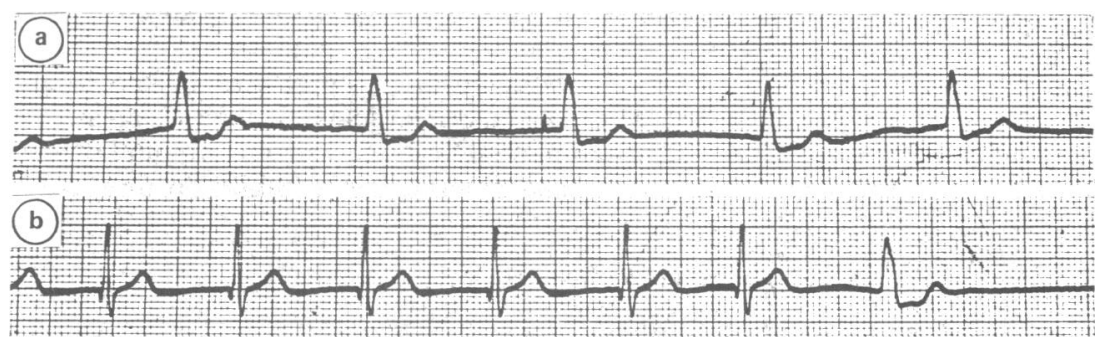

Electrocardiograms (a) before and (b) after intravenous atropine was given increased to 65 beats/minute and the QRS complex narrowed (figure). She recovered completely in the next 24 hours without further specific treatment.

Several investigations were performed. Baseline haematological and biochemical values, including activity of cardiac enzymes, were normal. No sequential ST or $\mathrm{T}$ wave changes were seen on electrocardiography, and a chest $x$ ray film and echocardiogram were both normal. Exercise testing was limited by leg fatigue at a low workload. Electrophysiological studies performed eight days after her admission showed minor dysfunction of the sinus node and isolated impairment of atrioventricular nodal conduction. Her serum was positive for antinuclear factor (1/256), but results of a DNA binding assay were in the normal range. No clear diagnosis was made. She was discharged for follow up as an outpatient.

Two months later she was again admitted with a symptomatic junctional bradycardia that resolved spontaneously within hours. Because of these repeated episodes a dual chamber sequential permanent pacemaker was inserted. A further brief admission with hypotension occurred in November 1985, at which time the pacemaker was functioning satisfactorily.

Early in 1986 she was admitted with profound hypotension, convulsions, and vomiting. Her heart rate was 72 beats/minute, and an electrocardiogram confirmed sequential atrioventricular pacing. Despite volume expansion guided by central venous pressure monitoring and inotropic support she remained hypotensive and oliguric for eight hours, but she eventually made a full recovery.

An interview with her partner elicited that he regularly attended the hospital with ischaemic heart disease. Despite recent coronary artery surgery he had had frequent admissions with chest pain and was being treated with propranolol and verapamil. Both he and 
the patient denied vigorously that she had ingested either of these drugs, but thin layer chromatography of the patient's urine showed a peak corresponding to propranolol. By the time this result became available the patient had discharged herself. She did not attend for follow up and was not readmitted to this hospital. Her general practitioner reported a long history of personality disturbance and antisocial behaviour, including alcohol abuse, domestic violence, and child neglect; offers of psychiatric help had been refused.

\section{Comment}

The clinical features of cardiovascular collapse, atrial asystole and junctional bradycardia, convulsions, and rapid recovery are well documented after overdoses of $\beta$ blockers. ${ }^{23}$ The ready availability of the drugs and the findings on chromatography provide circumstantial evidence that propranolol was the cause of this patient's symptoms, but we were unable to retrieve any serum for assay.

Factitious illness due to ingestion of drugs (for example, diuretics, laxatives, insulin, thyroxine, or warfarin) is well recognised. ${ }^{4}$ Patients may seem quite plausible and may be rigorously investigated. We know of no reports of repeated overdoses of $\beta$ blockers that have led to the insertion of a permanent pacemaker. The pacemaker may have been lifesaving in our patient as it maintained a reasonable heart rate during her most severe episode.

Surreptitious ingestion of drugs should be considered in any patient presenting with a bizarre or unexplained illness. A careful history taken from a relative or acquaintance, exploring the social background and availability of drugs, may give a clue to the true nature of the illness.

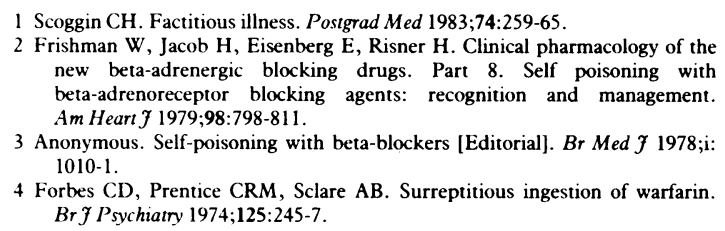

4 Forbes CD, Prentice CRM, Sclare AB. Surreptitious ingestion of warfarin. Br f Psychiatry 1974;125:245-7.

Accepted 27 October 1988

\section{Should recent dental treatment exclude potential blood donors?}

\section{A Nouri, T W MacFarlane, D MacKenzie, D A McGowan}

Departments of Oral Surgery and Oral Medicine and Pathology, Glasgow Dental Hospital and School, Glasgow G2 3JZ A Nouri, DDS, research fellow T W MacFarlane, FRCPATH, reader

D MacKenzie, FIMLs, chief medical laboratory scientific officer

D A McGowan, FDSRCS, professor

Correspondence to: $\mathrm{Mr}$ Nouri.

Br.Med f 1989;298:295
In at least some blood collection services potential donors who have had dental treatment within three days before donation are excluded ${ }^{\prime 2}$ to avoid the possibility of donated blood being contaminated by bacteria owing to bacteraemia after dental treatment. There is ample evidence that bacteraemia occurs after certain forms of dental treatment, ${ }^{3}$ defined as extraction, scaling, and surgery including the gingival tissue by the working party of the British Society for Antimicrobial Chemotherapy. ${ }^{4}$ Although bacteraemia is probably transient, there is little conclusive proof. Therefore we investigated the duration of bacteraemia after dental extraction.

\section{Patients, methods, and results}

Twenty two male and two female patients having dental extraction agreed to participate in the study and signed a consent form approved by the area dental ethical committee. All patients were fit and were not receiving antibacterial treatment. The skin overlying the right antecubital vein was scrubbed with povidoneiodine for 30 seconds and swabbed with $70 \%$ (vol/vol) isopropyl alcohol. A 19 gauge butterfly cannula was inserted into the vein and secured in place with adhesive tape. Ten $\mathrm{ml}$ of blood was collected before a local anaesthetic was given and at five, 15, and 30 minutes after completion of the extraction. The four samples of blood from each patient were injected into Oxoid blood culture bottles (Oxoid, Basingstoke, Hampshire) and incubated at $37^{\circ} \mathrm{C}$ for at least seven days. Subcultures were taken daily and inoculated on to Columbia agar supplemented with $7 \cdot 5 \%$ horse blood, vitamin $\mathrm{K}$, and haemin and incubated anaerobically at $37^{\circ} \mathrm{C}$ for four days. Representative colonies were subcultured to obtain pure cultures and identified by the criteria of atmospheric requirements for growth and microscopic morphology after Gram's staining and by the Analytical Profile Index 20A and 20 Strep.

Eighteen of 24 patients developed detectable bac- teraemia after dental extraction. The number of samples positive for bacteria decreased to eight by 15 minutes after extraction, and with one exception bacteria could not be isolated from the samples collected at 30 minutes. The table shows the bacteria isolated; at five minutes Streptococcus milleri was the commonest (seven samples); followed by $S$ sanguis I (six), $S$ mitis (five), and $S$ sanguis II (four). In 10 samples a single species was isolated, in two two species, and in six three or four species.

Number of positive bacterial cultures obtained from blood collected up to 30 minutes after dental extraction in 24 patients

\begin{tabular}{lccc}
\hline Organism & 5 Minutes & 15 Minutes & 30 Minutes \\
\hline Streptococcus milleri & 7 & 2 & \\
S sanguis I & 6 & 1 & \\
S sanguis II & 4 & 3 & \\
S mitis & 5 & & \\
S mutans & 2 & & \\
Peptostreptococcus spp & 1 & & \\
Bacteroides intermedius & 1 & 1 & \\
B melaninogenicus & 2 & & \\
Veillonella spp & 2 & 1 & \\
Lactobacillus fermentum & 1 & 1 & \\
Lacidophilus & 1 & & \\
Actinomyces naeslundii & &
\end{tabular}

\section{Comment}

Despite the use of careful techniques, which confirmed bacteraemia in $75 \%$ of cases at five minutes after extraction, only one sample collected at 30 minutes gave a positive result. As extraction is the dental procedure most likely to cause bacteraemia the results suggest that the risk of bacteraemia persisting for more than an hour after dental treatment is negligible. As a result there seems to be no justification in excluding a potential blood donor if he or she has received dental treatment more than one hour before.

1 Ness PM, Perkins HA. Transient bacteremia after dental procedures and other minor manipulations. Transfusion 1980:20:82-5.

2 Brozovic B, Brozovic M. Manuul of clinical blood transfusion. Edinburgh: Churchill Livingstone, 1986:121.

3 Everett ED, Hirschman JV. Transient bacteremia and endocarditis prophylaxis. A review. Medicine 1977;56:61-77.

4 Working Party of the British Society for Antimicrobial Chemotherapy. The antibiotic prophylaxis of infective endocarditis. Lancet 1982;ii:1323-6.

5 Bender IB, Pressman RS, Tashman SG. Comparative effect of local and systemic antibiotic therapy in the prevention of post extraction bacteremia. I Am Dent Assoc 1958;57:55-66.

(Accepted 20 October 1988) 